\title{
What factors counteract mid-term survival following endovascular repair of abdominal aortic aneurysms?
}

\author{
Ertekin Utku Ünal, Hakkı Zafer İscan, Bekir Bogachan Akkaya, İsa Civelek, Mehmet Karahan, Ece Celikten, \\ Göktan Askin, Hayrettin Levent Mavioğlu, Mehmet Ali Özatik
}

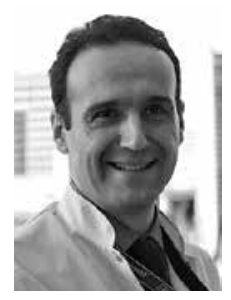

Department of Cardiovascular Surgery, Ankara City Hospital, Ankara, Turkey

Kardiochir Torakochir Pol 2021; 18 (1): 8-14

\begin{abstract}
Introduction: Endovascular aortic aneurysm repair (EVAR) for abdominal aortic aneurysm (AAA) is increasingly used, and has become the standard treatment option for AAA.

Aim: To evaluate the outcomes and predictors of survival of endovascular treatment of AAA in the short- and medium-term. Material and methods: A total of 222 patients having endovascular AAA repair between January 2013 and December 2019 by the same surgical team were included in the study. Patient demographics, perioperative and follow-up data including mortality, complications, and need for secondary intervention were collected. The primary endpoint was all-cause mortality. Kaplan-Meier analysis was conducted for survival and Cox regression models were assessed for predictors of survival.

Results: The median age was 70 years, with male predominance (202 patients, $91 \%$ ). Thirty-day mortality was $1.8 \%$. Median follow-up to the primary endpoint was 20 months (range: 1-80 months). Survival rates at 1, 3, and 5 years were $93.5 \%, 81.4 \%$, and $62.2 \%$, respectively. Freedom from secondary intervention rates were $95.5 \%$ at 1 year, $88.7 \%$ at 3 years, and $82.1 \%$ at 5 years. Cox proportional hazard models showed that preoperative creatinine levels $\geq 1.8 \mathrm{mg} / \mathrm{dl}$ (hazard ratio $(\mathrm{HR})=2.68,95 \% \mathrm{Cl}: 1.21-6.42$, $p=0.027)$, haemoglobin levels $<10 \mathrm{gr} / \mathrm{dl}(\mathrm{HR}=3.38,95 \% \mathrm{Cl}: 1.16-9.90, p=0.026)$, ejection fraction $<30 \%(\mathrm{HR}=5.67,95 \% \mathrm{Cl}$ : $1.29-24.86, p=0.021)$, and AAA diameter $\geq 6.0 \mathrm{~cm}(\mathrm{HR}=2.20,95 \% \mathrm{Cl}: 1.01-4.81, p=0.049)$ were independently associated with mid-term survival.

Conclusions: EVAR is a safe procedure with low postoperative morbidity and mortality. This study confirms that the mid-term survival and results are favourable. However, the analysed factors in this study that predict reduced survival (high preoperative creatinine, low haemoglobin, low ejection fraction and larger aneurysms) should be judged when planning endovascular repair of AAA.
\end{abstract}

Key words: abdominal aortic aneurysm, aneurysm sac, endovascular aneurysm repair, mortality, reintervention.

\section{Introduction}

Endovascular aneurysm repair (EVAR) has become the preferred treatment modality for abdominal aortic aneurysm (AAA) [1, 2]. It is recognized that early and late outcome after endovascular procedures is comparable to and even better than open surgery to some extent [3-5]. There are some controversial arguments for the late survival benefit following the long-term results of randomized trials [3, 5-7]. The known early benefit of EVAR seems to be lost after several years [6, 7]. However, the OVER trial demonstrated non-consistent findings with the other 2 randomized trials [5]. Survival rates and identification of the predictors of late mortality after EVAR are important key factors to be assessed to ensure the real benefit of EVAR. Moreover, real world data along with randomized trials should be taken into consideration to make interpretations about outcomes and survival.

\section{Aim}

The aim of this paper is to emphasize the survival rates and predictors of reduced survival after EVAR procedure performed by a single team of endovascular surgery.

\section{Material and methods \\ Patients}

All patients who underwent endovascular AAA repair between January 2013 and December 2019 were identified retrospectively from the database of hospital records. Patient demographics, perioperative variables, and early and midterm outcomes were recorded from the hospital database and death certificates. This study follows the Declaration of Helsinki and the study design and protocol were reviewed and approved by the Institutional Review Board (Ankara Sehir Hastanesi, 1 Nolu Klinik Araştırmalar Etik Kurul Baskanliği, E1-19-161). The requirement for informed

Address for correspondence: Prof. Ertekin Utku Ünal, Department of Cardiovascular Surgery, Ankara City Hospital, Ankara, Turkey,

e-mail: utkuunal@gmail.com

Received: 27.09.2020, accepted: 28.01.2021. 
consent was waived due to the retrospective nature of the study.

Indications for EVAR included (1) AAA > $5.5 \mathrm{~cm}$ in maximum diameter, (2) saccular type of aneurysms, and (3) symptomatic aneurysms. Patients with hostile neck (defined as neck length $\leq 10 \mathrm{~mm}$ and/or reverse conical shaped necks) were all included in the study.

\section{EVAR procedure}

All EVAR procedures were performed in a hybrid operating room by a specific team of cardiovascular surgery. The unibody endografts were mainly used in the early period of the study. In more recent years, modular endografts have been used in our practice. The devices used in this study were the Ankura' ${ }^{\text {TM }}$ AAA (Lifetech) in 89 (40.1\%) patients, the $\mathrm{AFX}^{\circledR}$ (Endologix) in 68 (30.6\%) patients, the Endurant ${ }^{\mathrm{TM}} \|$ (Medtronic) in 58 (26.1\%) patients, the Gore ${ }^{\circledR}$ Excluder $^{\circledR}$ (Gore) in 5 (2.3\%) patients, and the E-vita Abdominal XT (Jotec) in $2(0.9 \%)$ patients.

The procedures were performed in the hybrid room under general (169 patients, 76.1\%) or loco-regional anaesthesia (53 patients, $23.9 \%$ ), based on the preference of the surgical team, anaesthesiologist, and patient. Modular endografts were deployed in standard fashion, and the technique for unibody endograft deployment has been previously described [8]. The Endologix AFX ${ }^{\circledR}$ device (unibody) consists of a main bifurcated unibody and a proximal aortic extension. This endograft is the only graft with anatomical fixation at the aortic bifurcation. The aortic extension is placed at the infrarenal position. Completion angiography was performed after the procedure. Type 1 endoleaks were treated by balloon angioplasty and placement of an extension cuff if needed. Type 2 endoleaks were followed.

\section{Postoperative surveillance}

Postoperative evaluation consisted of clinical and radiological assessment at discharge, 1 month, 6 months, 12 months, and annually thereafter. Computed tomographic examination and Doppler ultrasonography were performed at 1 month. If there were no type 1 or 3 endoleaks at first evaluation, subsequent assessments of endoleak and sac diameters were performed only by Doppler ultrasonography. Type 2 endoleaks were also assessed only by Doppler ultrasonography, because they are accepted as benign endoleaks in the absence of sac enlargement. If there was suspicion of sac enlargement at ultrasonographic examination, this finding was checked by tomography. Sac enlargement was defined as minimum of $5 \mathrm{~mm}$ enlargement compared to the preoperative diameter. Contrast angiography was performed at the hybrid room only when a secondary intervention was needed.

\section{Estimating the possible predictors for survival}

Possible predictors were assessed by 2 commonly used risk models for vascular surgery: the Vascular Quality Ini- tiative and the Vascular Study Group of New England risk prediction models [9-11]. The combined possible predictors of these 2 risk models were analysed in the current study as follows. The predefined patient demographics (age as a continuous variable, gender, and comorbid factors such as diabetes, chronic obstructive pulmonary disease, and concomitant cardiac disease) were identified. Urgent repair was defined as symptomatic aneurysm treated within 24-48 hours of admission. Preoperative renal insufficiency was defined as creatinine level $\geq 1.8 \mathrm{mg} / \mathrm{dl}$, and preoperative anaemia was defined as haematocrit values below $30 \%$. Furthermore, aneurysm diameter was categorized as $<6.0 \mathrm{~cm}$ or $\geq 6.0 \mathrm{~cm}[12]$.

\section{Statistical analysis}

The variables were investigated using visual (histograms, probability plots) and analytical methods (Kolmogorov-Smirnov/Shapiro-Wilk test) to determine the normality of their distribution. Normally distributed continuous variables were expresses as mean \pm standard deviation (SD) or median values with range if not normally distributed. Categorical variables were expressed as number and percentages. Demographic parameters, operating variables, and follow-up data were compared using the Mann-Whitney $U$ test and $\chi^{2}$ test. Wilcoxon test was conducted to analyse pre-operative and follow-up diameter of aneurysm sac. Kaplan-Meier analysis was conducted to demonstrate freedom from all-cause mortality and freedom from secondary interventions. The hazard ratio (HR) and 95\% confidence intervals $(\mathrm{Cl})$ were estimated with different Cox proportional hazard models to estimate the independent predictors of survival with adjustment of the predefined possible rick factors. A $p$-value of $<0.05$ was considered to be statistically significant, and all statistical analyses were performed using the SPSS for Windows version 15.0 statistical software program (SPSS Inc., Chicago, IL, USA).

\section{Results}

A total of 222 patients underwent EVAR procedure in a 7-year period, and the procedures were carried out by the same team of cardiovascular surgeons. Baseline characteristics of the patients are summarized in Table I. The median age of the patients was 70 years (range: 46-92 years) and the study population was predominantly male (202 patients, 91\%).

The median stay in the intensive care unit and in the hospital was 4 hours (range: 2-240 hours) and 2 days (range: 1-20 days), respectively. Perioperative features are reviewed in Table II.

In-hospital mortality was $1.8 \%$ (4 patients out of 222). Follow-up was available in all 218 survivors. Excluding 4 inhospital mortalities, routine follow-up of remainders was included in the outcome assessment. The median followup period was 20 months (range: $1-80$ months). The followup data are shown in Table III.

Five-year freedom from any endoleak was 65\% with a $95 \%$ confidence interval $(\mathrm{Cl})$ of $54.3-74.9 \%$. On the other 
Table I. Baseline characteristics of the patients

\begin{tabular}{lc} 
Parameter & $\begin{array}{c}n(\%) \\
(N=222)\end{array}$ \\
Age [years] & $70(46-92)$ \\
\hline Male gender & $202(91.0)$ \\
\hline ASA grade: & $15(6.8)$ \\
\hline 1 & $94(42.3)$ \\
\hline 2 & $82(36.9)$ \\
\hline 3 & $31(14.0)$ \\
\hline 4 & $149(67.1)$ \\
\hline Hypertension & $59(26.6)$ \\
\hline Diabetes & $66(29.7)$ \\
\hline Hyperlipidaemia & $71(32.0)$ \\
\hline Chronic obstructive pulmonary disease & $23(10.4)$ \\
\hline Renal disease & $105(47.3)$ \\
\hline Atherosclerotic cardiac disease/heart & $99(44.6)$ \\
failure & $13(5.9)$ \\
\hline Smoking & $55(20-67)$ \\
\hline Malignancy & $60(33-116)$ \\
\hline Ejection fraction (\%) & $119(57.8)$ \\
\hline AAA diameter [mm] & \\
\hline$\geq 6.0 \mathrm{~cm}$ & \\
\hline AAA a & \\
\hline
\end{tabular}

AAA - abdominal aortic aneurysm, ASA - American Society of Anesthesiologists.

hand, freedom from type 1 a endoleaks, type $1 \mathrm{~b}$ endoleaks, type 2 endoleaks, and type 3 endoleaks was $97.5 \%(95 \% \mathrm{Cl}$ : 95.1-99.9\%), 92.5\% (95\% Cl: 85.2-99.8\%), 83.9\% (95\% Cl: 74.1-93.7\%), and $86.5 \%$ (95\% Cl: 75.5-97.5\%), respectively.

There were 36 (16.5\%) late deaths. Kaplan-Meier survival analysis revealed that overall survival at 1,3 , and 5 years was $93 \%, 81 \%$, and $62 \%$, respectively (Figure 1). Freedom from secondary intervention was $96 \%, 89 \%$, and $82 \%$ respectively for 1,3 , and 5 years (Figure 2). Indications for secondary intervention (endovascular or open) were type III endoleak (6 patients), stent-graft limb thrombosis (4 patients), type lb endoleak (4 patients), type la endoleak (3 patients), and vascular access problems (2 patients) (Table III).

Aneurysm sac diameter tended to be decreased after the procedure regarding to the preoperative measurements (from median $60 \mathrm{~mm}$ to $58 \mathrm{~mm}, p=0.047$ ). At the follow-up period, $86 \%$ of aneurysms were detected to be decreased in size or remained stable, when considering an increase of $5 \mathrm{~mm}$ of diameter as an enlargement.

\section{Predictors of survival}

Multivariate Cox regression models revealed that the independent predictors for late mortality were the creatinine $\geq 1.8 \mathrm{mg} / \mathrm{dl}$ (adjusted $\mathrm{HR}=2.68 ; 95 \% \mathrm{Cl}: 1.21-6.42$; $p=0.027$ ), hemoglobin < $10 \mathrm{~g} / \mathrm{dl}$ (adjusted $\mathrm{HR}=3.38$; 95\% Cl: 1.16-9.90; $p=0.026$ ), ejection fraction <30\% (adjusted $\mathrm{HR}=5.67 ; 95 \% \mathrm{Cl}: 1.29-24.86)$ and AAA diameter
Table II. Perioperative features

\begin{tabular}{|c|c|}
\hline Features & $\begin{array}{c}n(\%) \text { or median (range) } \\
(N=222)\end{array}$ \\
\hline General anaesthesia & $169(76.1)$ \\
\hline Local/regional anaesthesia & $53(23.9)$ \\
\hline \multicolumn{2}{|l|}{ Type of endograft: } \\
\hline Unibody (AFX® (Endologix)) & $68(30.6)$ \\
\hline Modular: & $154(69.4)$ \\
\hline Ankura ${ }^{\mathrm{TM}}$ AAA (Lifetech) & $89(40.1)$ \\
\hline Endurant ${ }^{T M} \|$ (Medtronic) & $58(26.1)$ \\
\hline Gore ${ }^{\circledR}$ Excluder ${ }^{\circledR}$ (Gore) & $5(2.3)$ \\
\hline E-vita Abdominal XT (Jotec) & $2(0.9)$ \\
\hline $\begin{array}{l}\text { Aorto-uni-iliac endograft } \pm \text { fem-fem } \\
\text { bypass }\end{array}$ & $4(1.8)$ \\
\hline Duration of procedure [minutes] & $120(90-360)$ \\
\hline Fluoroscopy time [minutes] & $16(6-78)$ \\
\hline Amount of contrast agent [ml] & $60(20-160)$ \\
\hline Length of intensive care unit stay [hours] & $4(2-240)$ \\
\hline Length of hospital stay [days] & $2(1-20)$ \\
\hline In-hospital mortality & $4(1.8)$ \\
\hline
\end{tabular}

Table III. Follow-up data

\begin{tabular}{|c|c|c|}
\hline Data & $\begin{array}{l}n(\%) \text { or median (range) } \\
(N=218)\end{array}$ & Reintervention \\
\hline Endoleaks: & $35(16.1)$ & \\
\hline Type la & $3(1.4)$ & 3 proximal extensions \\
\hline \multirow[t]{2}{*}{ Type lb } & \multirow[t]{2}{*}{$6(2.8)$} & 4 distal extensions \\
\hline & & 2 untreated \\
\hline Type II & $17(7.8)$ & $\begin{array}{l}17 \text { untreated } \\
\text { (follow-up) }\end{array}$ \\
\hline \multirow[t]{3}{*}{ Type III } & \multirow[t]{3}{*}{$9(4.1)$} & 4 open conversion \\
\hline & & $\begin{array}{l}2 \text { endovascular } \\
\text { relining }\end{array}$ \\
\hline & & $\begin{array}{l}3 \text { untreated (patient } \\
\text { preference) }\end{array}$ \\
\hline \multirow[t]{2}{*}{ Limb occlusion } & \multirow[t]{2}{*}{$6(2.8)$} & $\begin{array}{c}4 \text { femoro-femoral } \\
\text { bypasses }\end{array}$ \\
\hline & & 2 untreated \\
\hline $\begin{array}{l}\text { Late conversion } \\
\text { to open surgery }\end{array}$ & $4(1.8)$ & \\
\hline $\begin{array}{l}\text { Secondary } \\
\text { intervention }\end{array}$ & $19(8.7)$ & \\
\hline Late mortality & $36(16.5)$ & \\
\hline
\end{tabular}

$\geq 6.0 \mathrm{~cm}$ (adjusted $\mathrm{HR}=2.20 ; 95 \% \mathrm{Cl}: 1.01-4.81 ; p=0.049$ ) (Table IV). Age, gender, and symptomatic status of the patient did not interfere with the late survival of the patients. For further analysis, follow-up variables such as endoleak presence, endoleak type, reintervention, and sac enlargement $(>5 \mathrm{~mm}$ ) were also assessed by hazard models. 


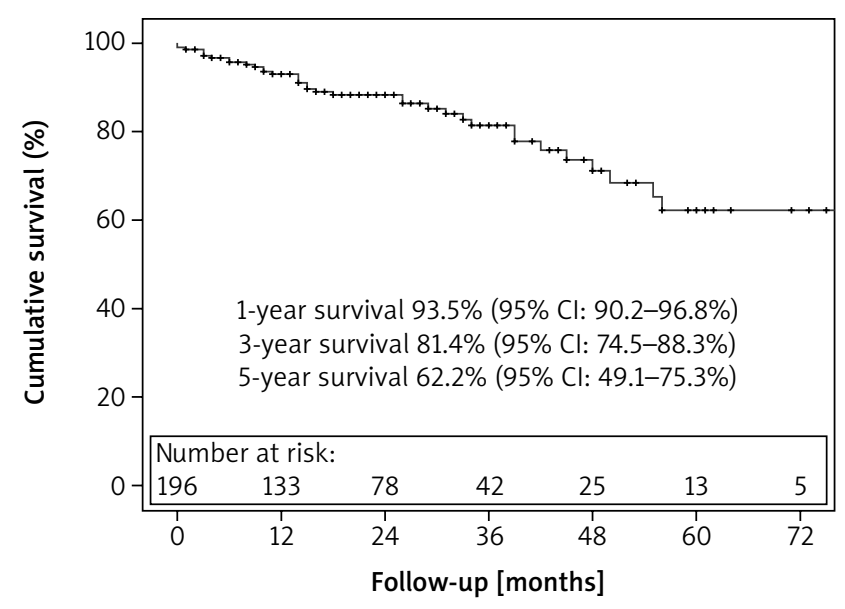

Figure 1. Kaplan-Meier estimate of cumulative survival

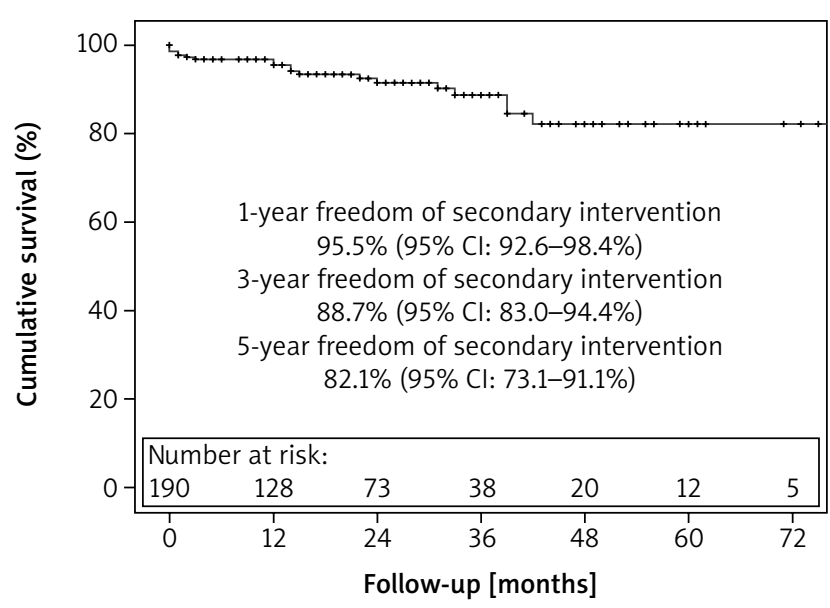

Figure 2. Kaplan-Meier estimate of freedom from secondary intervention

Table IV. Predictors of survival (unadjusted and adjusted hazard ratios analysed by Cox regression analysis)

\begin{tabular}{|c|c|c|c|c|c|c|}
\hline \multirow[t]{2}{*}{ Parameter } & \multicolumn{3}{|c|}{ Unadjusted analysis } & \multicolumn{3}{|c|}{ Adjusted analysis* } \\
\hline & $P$-value & $\mathrm{HR}$ & $95 \% \mathrm{Cl}$ & $P$-value & $\mathrm{HR}$ & $95 \% \mathrm{Cl}$ \\
\hline Age (continuous variable) & 0.056 & 1.05 & $1.00-1.10$ & & & \\
\hline Gender & 0.209 & 0.04 & $0.00-5.86$ & & & \\
\hline Creatinine $>1.8 \mathrm{mg} / \mathrm{dl}$ & 0.002 & 3.70 & $1.61-8.48$ & 0.027 & 2.68 & $1.21-6.42$ \\
\hline Haemoglobin $<10 \mathrm{~g} / \mathrm{dl}$ & 0.003 & 4.91 & $1.71-14.13$ & 0.026 & 3.38 & $1.16-9.90$ \\
\hline COPD & 0.716 & 1.14 & $0.57-2.25$ & & & \\
\hline DM & 0.572 & 0.80 & $0.36-1.75$ & & & \\
\hline$C A D \pm C A B G$ & 0.107 & 1.78 & $0.88-3.57$ & & & \\
\hline CABG only & 0.504 & 1.28 & $0.63-2.60$ & & & \\
\hline$E F<30 \%$ & 0.023 & 5.44 & $1.26-23.56$ & 0.021 & 5.67 & $1.29-24.86$ \\
\hline Symptomatic aneurysm & 0.494 & 1.27 & $0.64-2.53$ & & & \\
\hline AAA diameter $\geq 6.0 \mathrm{~cm}$ & 0.010 & 2.70 & $1.27-5.75$ & 0.049 & 2.20 & $1.01-4.81$ \\
\hline \multicolumn{7}{|l|}{ Follow-up variables: } \\
\hline EL & 0.944 & 0.97 & $0.40-2.34$ & & & \\
\hline EL other than type II & 0.091 & 2.14 & $0.89-5.17$ & & & \\
\hline Re-intervention & 0.485 & 1.40 & $0.54-3.62$ & & & \\
\hline Sac enlargement $(>5 \mathrm{~mm})$ & 0.029 & 3.78 & $1.15-12.45$ & & & \\
\hline
\end{tabular}

*Adjustment of covariates were based on age, gender, diabetes, hypertension, chronic obstructive pulmonary disease, cardiac status and presence of symptoms. AAA - abdominal aortic aneurysm, CABG -, coronary artery bypass grafting, CAD - coronary artery disease, Cl - confidence interval, COPD - chronic obstructive pulmonary disease, DM - diabetes mellitus, EF - ejection fraction, EL - endoleak, HR - hazard ratio.

Among these covariates, sac enlargement was found to be related with survival only in univariate analysis $(H R=3.78$, $95 \% \mathrm{Cl}: 1.15-12.45 ; p=0.029$ ).

\section{Discussion}

This report presents the mid-term outcome (median follow-up of 20 months) and predictors of survival after endovascular procedures with the use of all type of available endografts for the treatment of AAA by our single endovascular team. Freedom from all-cause mortality was 93\% at 1 year, $81 \%$ at 3 years, and $62 \%$ at 5 years. The main predictors of lower survival rates after EVAR were poor ventricular function, aneurysms above $6 \mathrm{~cm}$, and various comorbidities such as decreased renal function and anaemia.

In the past 2 decades, EVAR has increasingly become the standard treatment modality for non-complex infrarenal AAA [2]. EVAR has numerous advantages, especially in early survival benefit compared to open surgery, including the fact that the procedure has a minimally invasive nature and has a shorter recovery period.

During a median follow-up of 20 months 36 (16.5\%) deaths occurred in our study population. The 5 -year overall mortality was documented as $73.6 \%$ in a meta-analysis of 4 randomized trials [3]. The main controversy of this 
reported value is the selection criteria of the patients in the randomized trials, and all the patients in the trial were within the limits of the IFU. The numbers in the real world are slightly different from those in the randomized trials. The ENGAGE registry, which documented the outcomes of a single endograft (Medtronic Endurant ${ }^{\mathrm{TM}}$ ), reported that $17.8 \%$ of 1263 patients were outside the IFU limits and more than $10 \%$ had hostile necks. The 5 -year overall survival rate was reported as $67 \%$ in the ENGAGE registry [13]. Other earlier real-world reports have shown similar survival rates between $63 \%$ and $72 \%$ as well $[4,12,14-19]$. The survival rates of the current study occurred as $93 \%$ at 1 year, $81 \%$ at 3 years, and $62 \%$ at 5 years, which is highly comparable with the real-world data. On the other hand, Jeon-Slaughter et al. demonstrated that inferior mid-term survival after EVAR is independently associated with larger AAA diameters, especially above $6.0 \mathrm{~cm}$ [12]. Five-year survival rates of $<6.0 \mathrm{~cm}$ and $\geq 6.1 \mathrm{~cm}$ were $73 \%$ and $52 \%$, respectively, in the current study, which is comparable with the above-mentioned report.

Anatomical factors predicting survival after EVAR are the main topic of several studies in the literature $[9,10,12$, 20-22]. Aneurysm diameter, the anatomical properties of the aneurysm, and the neck angle were determined to be associated with midterm survival [22]. The initial aneurysm diameter independently predicted mortality in the long term. There was an almost 3-fold increase in mortality risk among patients with initial aneurysm diameter $\geq 6.0 \mathrm{~cm}$ in this study. Similarly, a recent study investigating the Vascular Quality Initiative database demonstrated a 1.5-fold increase of 5-year mortality at patients with large aneurysms $(\geq 6.5 \mathrm{~cm})$ [23]. Jeon-Slaughter et al. reported increased mid-term mortality risk with aneurysm size greater than $6.0 \mathrm{~cm}$ [12]. Furthermore, shorter life expectancy and higher rupture risk for endovascularly treated large aneurysms were documented by Zarins et al. [24]. The median diameter of AAA in our series was $60 \mathrm{~mm}, 58 \%$ of which were equal to or above $60 \mathrm{~mm}$. The majority of reports and registries assessing predictors for mortality show a mean aneurysm diameter of between 5.5 and $6.0 \mathrm{~cm}[9,10,21,24]$. The registry of the Vascular Quality Initiative, which is composed of over 18,000 EVAR patients, reported to have aneurysms above $6.0 \mathrm{~cm}$ in only $24 \%$ of the registry [9]. Moreover, the mean aneurysm diameter was reported as $58 \mathrm{~mm}$ in the Vascular Study Group of New England risk prediction model [10]. The 3-fold increase of mortality risk in our series, which is more than other series, may be clarified by the relative increased diameter of our patient population.

In addition to aneurysm diameter, some demographic features and comorbidities have been found to decrease survival for EVAR patients [9, 11, 21]. The simplified risk score model that was mentioned in the report of Neal et al. recognized that low ejection fraction has a very high score (+5 score) for risk prediction [11]. Similarly, preoperative ejection fraction below 30 was predictive of mortality, with a 5-fold increased risk in our study. Piffaretti et al. reported a similar predictive value of heart failure on late all-cause mortality [25]. In addition, several other studies also have documented heart failure as a risk factor for long-term mortality [26-29].

On the other hand, age, gender, and some comorbidities such as diabetes and chronic obstructive pulmonary disease were not associated with survival. The association between survival and age along with gender has been previously reported by numerous studies $[9,10,21]$. The majority of the studies reporting predictors of survival have a mean age of over 70 years $[20,25,28]$. A limited number of studies could not associate age with survival [30, 31]. The relatively young population and small number of study subjects may be the reason for the lack of a relationship between age and survival.

Gender is generally reported as a covariate for survival [28, 32-34], although there are some controversies about its predictive value in other studies [19, 28, 35-37]. Women who undergo endovascular repair tend to be older than men in most of the studies and the older age may contribute to its predictive effect. However, the median age of women in our study was not significantly different from the men's age. The results of our study are nevertheless reliable in highvolume reports [19, 28, 35-37]. The other confounding issue was the male predominance in our study (91\%), which may impede the clarification of results regarding gender.

Alternatively, overall all-cause mortality in the midterm was significantly 3 times lower for the patients without renal disease or anaemia. Saratzis et al. concluded that impaired renal function was independently associated with an increase mortality following EVAR [30]. Similarly, Khashram et al. identified baseline renal impairment (creatinine $>1.7 \mathrm{mg} / \mathrm{dl}$ ) as an important predictor of survival [28]. Additionally, there are several other studies reporting hazard ratios between 1.6 and 2.1, and confirming the results of our study [34, 38, 39]. On the other hand, concerning anaemia, a few single-centre observational studies have reported an association with reduced mid- and long-term survival $[38,40]$. Another observational study regarding severe anaemia ( $<10 \mathrm{gr} / \mathrm{dl}$ ), which is similar to our definition, reported 2.6-fold increased risk of in-hospital mortality after EVAR [41]. Furthermore, our study is unique given that poor midterm survival is associated preoperative severe anaemia $(H R=3.4)$. Anaemia may be assoicated with a diminished cardiac reserve and other comorbid conditions. The underlying condition may be addressed to overcome this condition.

This study includes some notable limitations. Firstly, these results were analysed retrospectively and evaluated from a single endovascular team, which may have caused a selection bias. The overall number of the study population was relatively low. Secondly, unfortunately, the cause of late deaths could not be identified for some patients. Therefore, analysis for aneurysm-related death and nonaneurysm-related death could not be constructed for this study. Lastly, considerably short follow-up time may be a limitation to assess the predictors of survival accurately. On the other hand, projection of 5 year survival of this patient cohort is comparable to the literature. 


\section{Conclusions}

The outcomes of EVAR patients in the current study demonstrates safety and acceptable durability of the endografts in AAA patients at 5 years with a survival rate of over $60 \%$ and freedom from secondary intervention exceeding $80 \%$. Large aneurysms, low ejection fraction, poor renal function, and anaemia are independent predictors of reduced survival after endovascular repair of the aneurysm. Longer-term follow-up is expected to be reported through 10 years.

\section{Disclosure}

The authors report no conflict of interest.

\section{References}

1. Chaikof EL, Dalman RL, Eskandari MK, Jackson BM, Lee WA, Mansour MA Mastracci TM, Mell M, Murad MH, Nguyen LL, Oderich GS, Patel MS, Schermerhorn ML, Starnes BW. The Society for Vascular Surgery practice guidelines on the care of patients with an abdominal aortic aneurysm. J Vasc Surg 2018; 67: 2-77.e72

2. Wanhainen A, Verzini F, Van Herzeele I, Allaire E, Bown M, Cohnert T, Dick F, van Herwaarden J, Karkos C, Koelemay M, Kölbel T, Loftus I, Mani K, Melissano G, Powell J, Szeberin Z, Esvs Guidelines Committee, de Borst GJ, Chakfe N Debus S, Hinchliffe R, Kakkos S, Koncar I, Kolh P, Lindholt JS, de Vega M, Vermassen F, Document Reviewers, Björck M, Cheng S, Dalman R, Davidovic L, Donas K, Earnshaw J, Eckstein HH, Golledge J, Haulon S, Mastracci T, Naylor R, Ricco JB, Verhagen H. Editor's Choice - European Society for Vascular Surgery (ESVS) 2019 Clinical Practice Guidelines on the management of abdominal aorto-iliac artery aneurysms. Eur J Vasc Endovasc Surg 2019; 57: 8-93.

3. Powell JT, Sweeting MJ, Ulug P, Blankensteijn JD, Lederle FA, Becquemin JP, Greenhalgh RM, EVAR-1, DREAM, OVER and ACE Trialists. Meta-analysis of individual-patient data from EVAR-1, DREAM, OVER and ACE trials comparing outcomes of endovascular or open repair for abdominal aortic aneurysm over 5 years. Br J Surg 2017; 104: 166-178.

4. Broos PPHL, W't Mannetje Y, Stokmans RA, Houterman S, Corte G, Cuypers PWM, Teijink JAW, van Sambeek MRHM. A 15-year single-center experience of endovascular repair for elective and ruptured abdominal aortic aneurysms. J Endovasc Ther 2016; 23: 566-573.

5. Lederle FA, Kyriakides TC, Stroupe KT, Freischlag JA, Padberg Jr FT, Matsumura JS, Huo Z, Johnson GR; OVER Veterans Affairs Cooperative Study Group. Open versus endovascular repair of abdominal aortic aneurysm. N Engl J Med 2019; 380: 2126-2135.

6. Patel R, Sweeting MJ, Powell JT, Greenhalgh RM, EVAR trial investigators. Endovascular versus open repair of abdominal aortic aneurysm in 15-years' follow-up of the UK endovascular aneurysm repair trial 1 (EVAR trial 1): a randomised controlled trial. Lancet 2016; 388: 2366-2374.

7. van Schaik TG, Yeung KK, Verhagen HJ, de Bruin JL, van Sambeek MRH, Balm R, Zeebregts CJ, van Herwaarden JA, Blankensteijn JD; DREAM Trial Participants. Long-term survival and secondary procedures after open or endovascular repair of abdominal aortic aneurysms. J Vasc Surg 2017; 66: 1379-1389.

8. Avcı T, Askun G, Boğaçhan Akkaya B, Ece Çelikten A, Salman N, Utku Ünal E, Zafer isşcan H, Alp Küçüker Ş. The effects of anesthesia types on early postoperative results in elective endovascular repair of aortic aneurysms. Turk J Vasc Surg 2019; 28: 159-164.

9. Bertges DJ, Neal D, Schanzer A, Scali ST, Goodney PP, Eldrup-Jorgensen J, Cronenwett JL, Vascular Quality Initiative. The Vascular Quality Initiative Cardiac Risk Index for prediction of myocardial infarction after vascular surgery. J Vasc Surg 2016; 64: 1411-1421.

10. Eslami MH, Rybin D, Doros G, Kalish JA, Farber A. Comparison of a Vascular Study Group of New England risk prediction model with established risk prediction models of in-hospital mortality after elective abdominal aortic aneurysm repair. J Vasc Surg 2015; 62: 1125-1133.e1122.

11. Neal D, Beck AW, Eslami M, Schermerhorn ML, Cronenwett JL, Giles KA, Carroccio A, Jazaeri O, Huber TS, Upchurch Jr GR, Scali ST. Validation of a preop- erative prediction model for mortality within 1 year after endovascular aortic aneurysm repair of intact aneurysms. J Vasc Surg 2019; 70: 449-461.e443.

2. Jeon-Slaughter H, Krishnamoorthi H, Timaran D, Wall A, Ramanan B, Banerjee S, Timaran CH, Modrall JG, Tsai S. Effects of abdominal aortic aneurysm size on mid- and long-term mortality after endovascular aneurysm repair. J Endovasc Ther 2019; 26: 231-237.

13. Teijink JAW, Power AH, Böckler D, Peeters $P$, van Sterkenburg S, Bouw man LH, Verhagen HJ, Bosiers M, Riambau V, Becquemin JP, Cuypers P, van Sambeek M. Editor's Choice - Five year outcomes of the endurant stent graft for endovascular abdominal aortic aneurysm repair in the ENGAGE Registry. Eur J Vasc Endovasc Surg 2019; 58: 175-181.

14. Schermerhorn ML, Buck DB, O'Malley AJ, Curran T, McCallum JC, Darling J, Landon BE. Long-term outcomes of abdominal aortic aneurysm in the Medicare population. N Engl J Med 2015; 373: 328-338.

15. Verzini F, Romano L, Parlani G, Isernia G, Simonte G, Loschi D, Lenti M, Cao P. Fourteen-year outcomes of abdominal aortic endovascular repair with the Zenith stent graft. J Vasc Surg 2017; 65: 318-329.

16. Mertens J, Houthoofd S, Daenens K, Fourneau I, Maleux G, Lerut P, Nevelsteen A. Long-term results after endovascular abdominal aortic aneurysm repair using the Cook Zenith endograft. J Vasc Surg 2011; 54: 48-57.e42.

17. Bos WT, Tielliu IF, Zeebregts CJ, Prins TR, van den Dungen JJ, Verhoeven EL. Results of endovascular abdominal aortic aneurysm repair with the Zenith stent-graft. Eur J Vasc Endovasc Surg 2008; 36: 653-660.

18. Wisniowski B, Barnes M, Jenkins J, Boyne N, Kruger A, Walker PJ. Predictors of outcome after elective endovascular abdominal aortic aneurysm repair and external validation of a risk prediction model. J Vasc Surg 2011; 54: 644-653.

19. Gloviczki P, Huang Y, Oderich GS, Duncan AA, Kalra M, Fleming MD, Harm sen WS, Bower TC. Clinical presentation, comorbidities, and age but not female gender predict survival after endovascular repair of abdominal aortic aneurysm. J Vasc Surg 2015; 61: 853-861.e852.

20. Oliveira NFG, Ultee K, van Rijn MJ, Pinto JP, Raa ST, Gonçalves FB, Hoeks SE, Verhagen HJM. Anatomic predictors for late mortality after standard endovascular aneurysm repair. J Vasc Surg 2019; 69: 1444-1451.

21. Marques-Rios G, Oliveira-Pinto J, Mansilha A. Predictors of long-term mortality following elective endovascular repair of abdominal aortic aneurysms. Int Angiol 2018; 37: 277-285

22. Young ZZ, Balceniuk MD, Rasheed K, Mix D, Esce A, Ellis JL, Glocker RJ, Doyle AJ, Raman K, Stoner MC. Aortic anatomic severity grade correlates with midterm mortality in patients undergoing abdominal aortic aneurysm repair. Vasc Endovascular Surg 2019; 53: 292-296.

23. Jones DW, Deery SE, Schneider DB, Rybin DV, Siracuse JJ, Farber A, Schermerhorn ML, Vascular Quality Initiative. Differences in patient selection and outcomes based on abdominal aortic aneurysm diameter thresholds in the Vascular Quality Initiative. J Vasc Surg 2019; 70: 1446-1455.

24. Zarins CK, Crabtree T, Bloch DA, Arko FR, Ouriel K, White RA. Endovascular aneurysm repair at 5 years: does aneurysm diameter predict outcome? I Vasc Surg 2006; 44: 920-930.

25. Piffaretti G, Mariscalco G, Riva F, Fontana F, Carrafiello G, Castelli P. Abdominal aortic aneurysm repair: long-term follow-up of endovascular versus open repair. Arch Med Sci 2014; 10: 273-282.

26. Schlösser FJV, Vaartjes I, van der Heijden GJMG, Moll FL, Verhagen HJM, Muhs BE, de Borst GJ, Groenestege A TT, Kardaun JWPF, de Bruin A. Mortality after elective abdominal aortic aneurysm repair. Ann Surg 2010; 251: 158-164.

27. Mastracci TM, Greenberg RK, Hernandez AV, Morales C. Defining high risk in endovascular aneurysm repair. J Vasc Surg 2010; 51: 1088-1095.e1081.

28. Khashram M, Jenkins JS, Jenkins J, Kruger AJ, Boyne NS, Foster WJ, Walker PJ. Long-term outcomes and factors influencing late survival following elective abdominal aortic aneurysm repair: a 24-year experience. Vascular 2016; 24 115-125.

29. Lifeline Registry of EVAR Publications Committee. Lifeline registry of endovascular aneurysm repair: long-term primary outcome measures. J Vasc Surg 2005; 42: 1-10.

30. Saratzis A, Sarafidis P, Melas N, Saratzis N, Kitas G. Impaired renal function is associated with mortality and morbidity after endovascular abdominal aortic aneurysm repair. J Vasc Surg 2013; 58: 879-885.

31. Tsilimparis N, Mitakidou D, Hanack U, Deussing A, Yousefi S, Rückert RI. Effect of preoperative aneurysm diameter on long-term survival after endovascular aortic aneurysm repair. Vasc Endovasc Surg 2012; 46: 530-535.

32. Egorova NN, Vouyouka AG, McKinsey JF, et al. Effect of gender on long-term survival after abdominal aortic aneurysm repair based on results from the Medicare national database. J Vasc Surg 2011; 54: 1-12.e16. 
33. Mehta M, Byrne WJ, Robinson H, Roddy SP, Paty PSK, Kreienberg PB, Feustel P, Darling III RC. Women derive less benefit from elective endovascular aneurysm repair than men. J Vasc Surg 2012; 55: 906-913.

34. Grootenboer N, Hunink MGM, Hendriks JM, van Sambeek MRHM, Buth J, Collaborators E. Sex differences in 30-day and 5-year outcomes after endovascular repair of abdominal aortic aneurysms in the EUROSTAR study. J Vasc Surg 2013; 58: 42-49.e41.

35. Lee H, Clair D, Ouriel K. Ten-year comparison of all-cause mortality after endovascular or open repair of abdominal aortic aneurysms: a propensity score analysis. World J Surg 2012; 37: 680-687.

36. de Bruin JL, Baas AF, Heymans MW, Buimer MG, Prinssen M, Grobbee DE, Blankensteijn JD; DREAM Study Group. Statin therapy is associated with improved survival after endovascular and open aneurysm repair. J Vasc Surg 2014; 59: 39-44.e31.

37. Lo RC, Bensley RP, Hamdan AD, Wyers M, Adams JE, Schermerhorn ML Gender differences in abdominal aortic aneurysm presentation, repair, and mortality in the Vascular Study Group of New England. J Vasc Surg 2013; 57: 1261-1268.e1265.

38. Diehm N, Benenati JF, Becker GJ, Quesada R, Tsoukas Al, Katzen BT, Kovacs $M$. Anemia is associated with abdominal aortic aneurysm (AAA) size and decreased long-term survival after endovascular AAA repair. J Vasc Surg 2007; 46: 676-681.

39. Kertai MD, Boersma E, Westerhout CM, van Domburg R, Klein J, Bax JJ, van Urk H, Poldermans D. Association between long-term statin use and mortality after successful abdominal aortic aneurysm surgery. Am J Med 2004; 116: 96-103.

40. Ohrlander T, Dencker M, Acosta S. Morphological state as a predictor for reintervention and mortality after EVAR for AAA. Cardiovasc Intervent Radiol 2012; 35: 1009-1015.

41. Dakour-Aridi H, Nejim B, Locham S, Alshwaily W, Malas MB. Anemia and postoperative outcomes after open and endovascular repair of intact abdominal aortic aneurysms. J Vasc Surg 2019; 69: 738-751.e732. 